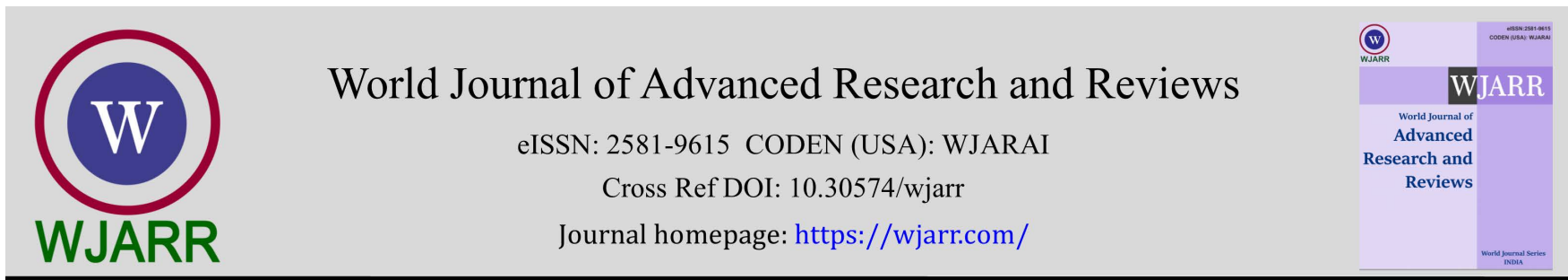

(RESEARCH ARTICLE)

\title{
Caregivers' burden of caring for children with chronic illnesses at a tertiary health facility in southern Nigeria
}

\author{
Gracia Ker Eke and Nsirimobu Ichendu Paul * \\ Department of Paediatrics, University of Port Harcourt Teaching Hospital, Nigeria.
}

World Journal of Advanced Research and Reviews, 2021, 10(01), 105-114

Publication history: Received on 24 February 2021; revised on 29 March 2021; accepted on 01 April 2021

Article DOI: https://doi.org/10.30574/wjarr.2021.10.1.0128

\begin{abstract}
Background: The responsibilities perceived by caregivers of children with chronic diseases can impose significant burden on their physical, emotional and mental well-being.

Objective: To explore the burden of caregivers of children with chronic illnesses at a tertiary-care health facility in southern Nigeria, in order to devise effective ways of reducing them.

Methodology: It was a descriptive cross-sectional survey amongst parents/caregivers of children with chronic illnesses in the Children's Outpatient clinics /wards and emergency room, who presented for care and/or follow-up visits between October and December 2020. A validated Caregiver Burden Scale (CBS) that assesses the level of burden in five domains: general strain, isolation, disappointment, emotional involvement and environment, was used to obtain data. Caregivers' and the children' socio-demographic characteristics were also ascertained and compared with the level of burden. Data were analyzed using SPSS version 25.0. A p-value of $<0.05$ was considered significant.
\end{abstract}

Result: A total of 109 caregivers completed the questionnaire. Half $(n=55 ; 50.5 \%)$ of the caregivers were aged 30 39years; 88 (80.7\%) were females; 58 (53.2\%) had post-secondary education and 51 (46.8\%) were self-employed. Of the 109 children studied, $70(64.2 \%)$ were males and the commonest diagnosis was sickle cell anaemia (SCA) (n=62; $56.9 \%$ ) followed by Human Immunodeficiency Virus (HIV) disease ( $\mathrm{n}=35 ; 32.1 \%)$. The age at diagnosis was 1 -5years in $70(64.2 \%)$ of cases while $76(69.7 \%)$ of them had received care for 1-5years. The mean caregiving burden score was highest in disappointment (2.0) and lowest in the domain of isolation (1.5), while the overall mean score was 1.7 $(S D=0.6)$. There was a statistically significant relationship between the caregivers' age and all the domains studied except the general strain, while the other socio-demographic variables had varying significance with the different domains of burden.

Conclusion: Severe burden of caregiving was experienced by more caregivers in the domains of disappointment and general strain while the isolation domain experienced the lowest frequency of caregivers with severe burden. Improving social support and advocacy to stakeholders, including the government to take over the financing of medical expenses of children with chronic diseases will reduce the burden of care experienced by their caregivers.

Keywords: Caregivers burden; Children; Chronic diseases; Tertiary facility

\section{Introduction}

Childhood chronic illness refers to conditions in paediatric patients that are usually prolonged in duration, do not resolve on their own, and are associated with impairment or disability [1]. The duration required for an illness to be

\footnotetext{
* Corresponding author: Dr Nsirimobu I. Paul

Department of Paediatrics, University of Port Harcourt Teaching Hospital, Nigeria.
}

Copyright (C) 2021 Author(s) retain the copyright of this article. This article is published under the terms of the Creative Commons Attribution Liscense 4.0. 
defined as chronic is generally greater than 12 months, but this can vary, and some organizations define it by limitation of function rather than a length of time [2]. With advances in medicine, infant and child mortality especially from infectious causes has decreased in most areas of the world, resulting in increased number of children living with chronic illnesses, which affect $13-27 \%$ of children [3].

Chronic illnesses in childhood undermine children and their family, which is their main base of support, as coping with the diagnosis can cause physical and psychological strain, especially for the primary caregiver who most of the time is the mother $[4,5,6]$. They can pose several limitations in self-care functions such as feeding, dressing, bathing, and mobility, which can result in requirement for long-term care that far exceed the usual needs of normal children [7]. Affected children may require frequent hospitalizations and continuous and/or special care, which cause enormous material costs to their families, contributing to depleting the household's finances, especially in developing countries where there is high level of poverty and inequitable distribution of wealth and resources $[5,8]$.

The responsibilities perceived by caregivers and the limitations induced by them and their family is referred to as caregiving burden [9]. It is defined as the caregivers' perceptions of the adverse effects of caregiving on their emotional, physical, mental, financial and social functioning, and this stems from the lack of established balance between care needs and other duties of the caregivers. It consists of subjective and objective dimensions. The objective caregiving burden is considered as the extent of time and effort required for supplying patients' needs including financial costs, family relations and social functions, while subjective caregiving burden is the degree of stress imposed on the caregivers when they face objective caregiving burden including mental, emotional and behavioral problems [10].

Literature indicates that providing care (or caregiving) to patients with chronic illnesses can negatively influence patient and caregiver's health outcomes [6-8,11]. Thus, it has been recommended that family caregivers confronted by significant psychosocial distress be targeted for effective interventions such as provision of information/ support, and promotion of positive coping styles among others, indicating the need to screen for those at risk [11,12].

Several instruments, which have been translated and validated for various languages, have been developed in order to measure the caregiver's level of burden, evaluating the variations in the burden of care for different illnesses [6].

In Nigeria, there are many different diseases affecting children that have a prolonged course and can lead to disability or impairment, including sickle cell anaemia (SCA), Human Immunodeficiency Virus (HIV)/ Acquired Immune deficiency Syndrome (AIDS), neurodevelopmental conditions, asthma, congenital heart disease, epilepsy and cancer, among others $[5,7,8,13,14]$. Though, the burden of caring for some of these diseases has been documented in some parts of the country, there is paucity of data in our region, the southern part of Nigeria. Thus, the present survey was conducted to explore the burden of caregivers who patronise our hospital with their children affected with chronic illnesses, in order to devise effective ways of reducing them.

\section{Material and methods}

This study was carried out at the University of Port Harcourt Teaching Hospital (UPTH), an 800-bedded federal tertiary health institution serving Rivers and the neighbouring States in southern Nigeria. It also serves as a general/referral centre for children in Port Harcourt and its environs.

It was a descriptive cross-sectional survey carried out between October and December 2020, amongst parents/caregivers of children who are being managed for various childhood chronic illnesses in the Department of Paediatrics, as they brought their children to the Children's Outpatient clinics /wards and emergency room for care and/or follow-up visits. The Children's Outpatient clinics are run on week days, while the wards and emergency room are opened 24/7. The department caters for children aged 0-17 years.

The instrument used for collection of data was the Caregiver Burden Scale (CBS), a 22-item validated scale that assesses the level of burden, referring to the domains of general strain (8 questions), isolation (3 questions), disappointment (5 questions), emotional involvement (3 questions) and environment (3 questions) $[15,16]$. The caregiver is asked to tick one of the four boxes (not at all, rarely, sometimes, often), with scores of 1 to 4 for each question. The mean score of caregiving burden in each domain was derived by calculating the mean score of items associated with that sub-scale. The total caregiving burden score was derived by calculating the mean scores of all items. A higher score indicated a greater burden. In this study, the answers "not at all" and "rarely" were categorized as low burden and "sometimes" and "often" as high burden. Then, caregiving burden was classified into two levels: low and high (severe). 
In addition, information related to the caregivers and the child socio-demographic characteristics were ascertained and compared with the level of burden. The minimum wage in Nigeria is 30,000 Naira (1 USD=450 Naira).

Investigators sought the help of interpreters to interact with participants who did not speak and/or understand the English or Pidgin English languages.

Permission to conduct the study was obtained from the Ethics Committee of the hospital and informed consent from the parents/caregivers of affected children. Data were entered into a Microsoft Excel Spread Sheet and analyzed using SPSS version 25.0. A p-value of $<0.05$ was considered significant.

\section{Results}

\subsection{Socio-demographic characteristics of the Caregivers}

A total of 109 caregivers caring for 109 children completed the questionnaire. Table 1 shows that 55 (50.5\%) of the caregivers were aged 30-39years, 88 (80.7\%) were females, 97 (89.0\%) were married, 58 (53.2\%) had post-secondary education, 51 (46.8\%) were self-employed, 52 (47.7\%) had an average monthly income of 31,000 - 150,000 naira.

Table 1 Socio-demographic Distribution of the caregivers.

\begin{tabular}{|c|c|c|}
\hline & Frequency $(n=109)$ & Percent \\
\hline \multicolumn{3}{|l|}{ Age Group } \\
\hline $20-29$ years & 10 & 9.2 \\
\hline $30-39$ years & 55 & 50.5 \\
\hline $40-49$ years & 30 & 27.5 \\
\hline$>50$ years & 14 & 12.8 \\
\hline \multicolumn{3}{|l|}{ Gender } \\
\hline Male & 21 & 19.3 \\
\hline Female & 88 & 80.7 \\
\hline \multicolumn{3}{|l|}{ Marital status } \\
\hline Single & 4 & 3.7 \\
\hline Married & 97 & 89 \\
\hline Separated & 4 & 3.7 \\
\hline Widowed & 4 & 3.7 \\
\hline \multicolumn{3}{|l|}{ Education } \\
\hline No Formal education & 4 & 3.7 \\
\hline Primary & 6 & 5.5 \\
\hline Secondary & 41 & 37.6 \\
\hline Post-Secondary & 58 & 53.2 \\
\hline \multicolumn{3}{|l|}{ Occupation } \\
\hline Farming & 7 & 6.4 \\
\hline Public servant & 15 & 13.8 \\
\hline Self-employed & 51 & 46.8 \\
\hline Teacher & 8 & 7.3 \\
\hline Trader & 24 & 22 \\
\hline Unemployed & 4 & 3.7 \\
\hline \multicolumn{3}{|c|}{ Average Monthly Income in Naira** } \\
\hline$<30000$ & 34 & 31.2 \\
\hline $31000-150000$ & 52 & 47.7 \\
\hline $151000-300000$ & 23 & 21.1 \\
\hline
\end{tabular}

\subsection{Distribution of Chronic disease condition in Parents/Caregivers}

Among the caregivers, 76 (69.7\%) had no underlying chronic illness while 25 (22.9\%) had HIV disease (Table 2). 
Table 2 Distribution of Chronic disease condition in Parent/Caregiver

\begin{tabular}{|l|l|l|}
\hline Chronic disease & Frequency $(\mathbf{n = 1 0 9})$ & Percent \\
\hline Hypertension & 1 & 0.9 \\
\hline HIV disease & 25 & 22.9 \\
\hline Physical disability & 4 & 3.7 \\
\hline SCA & 3 & 2.8 \\
\hline None & 76 & 69.7 \\
\hline
\end{tabular}

HIV: Human Immunodeficiency Virus; SCA: Sickle Cell Anaemia

\subsection{Distribution of the diagnoses and Demographic characteristics of the Children}

Of the 109 children studied, 70 (64.2\%) were males, 62 (56.9\%) had SCA while 35 (32.1\%) had HIV disease. The age at diagnosis was 1-5years in $70(64.2 \%)$ while $76(69.7 \%)$ of them had received care for 1-5years (Table 3).

Table 3 Distribution of the diagnoses and Demographic characteristics of the Children.

\begin{tabular}{|l|l|l|}
\hline & Frequency (n=109) & Percent \\
\hline Diagnoses & & \\
\hline SCA & 62 & 56.9 \\
\hline HIV disease & 35 & 32.1 \\
\hline Cancer & 8 & 7.3 \\
\hline Seizures & 4 & 3.7 \\
\hline Child's gender & & \\
\hline Male & 70 & 64.2 \\
\hline Female & 39 & 35.8 \\
\hline Age at diagnosis & & \\
\hline 1 - 5 years & 78 & 71.6 \\
\hline 6 - 10 years & 19 & 17.4 \\
\hline$>10$ years & 12 & 11 \\
\hline Duration of Care & & 6.2 \\
\hline 1 - 5 years & 76 & 21.1 \\
\hline 6 - 10 years & 23 & 9.7 \\
\hline$>10$ years & 10 & \\
\hline HIV: Human Immunodeficiency Virus; SCA- Sickle Cell Anaemia
\end{tabular}

\subsection{Level of burden among the caregivers for the various domains}

The level of caregivers' burden was low in all the domains studied, however, the area of disappointment (n=25; $22.9 \%)$ and general strain $(n=21 ; 19.3 \%)$ had the highest levels of severe caregivers' burden (Table 4$)$. The mean caregiving burden total score was $1.7(\mathrm{SD}=0.6)$. Mean score was highest in disappointment $(2.0)$ and lowest in the domain of isolation (0.6). 
Table 4 Distribution of level of burden among caregivers for the various domains.

\begin{tabular}{|l|l|l|l|l|l|}
\hline Domains & $\begin{array}{l}\text { Low } \\
\text { n (\%) }\end{array}$ & $\begin{array}{l}\text { High } \\
\text { n (\%) }\end{array}$ & $\begin{array}{l}\text { Total } \\
\text { n (\%) }\end{array}$ & $\begin{array}{l}\text { Mean } \\
\text { score }\end{array}$ & $\begin{array}{l}\text { Std } \\
\text { Deviation }\end{array}$ \\
\hline Disappointment & $84(77.1)$ & $25(22.9)$ & $109(100.0)$ & 2.0 & 0.7 \\
\hline General Strain & $88(80.7)$ & $21(19.3)$ & $109(100.0)$ & 1.8 & 03 \\
\hline Emotional Involvement & $98(89.9)$ & $11(10.1)$ & $109(100.0)$ & 1.6 & 0.5 \\
\hline Environment & $98(89.9)$ & $11(10.1)$ & $109(100.0)$ & 1.6 & 0.7 \\
\hline Isolation & $106(97.2)$ & $3(2.8)$ & $109(100.0)$ & 1.5 & 0.6 \\
\hline
\end{tabular}

\subsection{Distribution of Disappointment by demographic characteristics}

More caregivers $(n=25 ; 22.94 \%)$ were faced with disappointment as a burden in the care of their children compared to other domain of burden studied. Out of this, 12 (48.0\%) were aged 30-39years, 15 (60.0\%) were females while 13 (52.0\%) had low monthly income. There was a statistically significant relationship between the burden of disappointment and age $(\mathrm{p}=0.007)$, gender $(\mathrm{p}=0.003)$ and income $(\mathrm{p}=0.037)$ of the caregivers. Of the children of the caregivers, $18(72.0 \%)$ were males, 19 (76.0\%) had SCD, all (100\%) had the diagnosis made at age 1-5years while 19 $(76.0 \%)$ had received care for 1-5years. The burden of disappointment was statistically related to the age at diagnosis $(p=0.002)$ and duration of care $(p=0.0001)$ (Table 5).

Table 5 Distribution of Disappointment by Demographic information.

\begin{tabular}{|l|l|l|l|}
\hline & \multicolumn{1}{|c|}{$\begin{array}{c}\text { Low } \\
\mathbf{N}=\mathbf{( 7 7 . 0 6 \% )}\end{array}$} & $\begin{array}{c}\text { High } \\
\mathbf{n = 2 5} \mathbf{( 2 2 . 9 4 \% )}\end{array}$ & $\begin{array}{l}\text { Chi-square } \\
\text { (p-value) }\end{array}$ \\
\hline Age Group & & & \\
\hline 20 - 29 years & $4(4.76)$ & $6(24.0)$ & \\
\hline 30 - 39 years & $43(51.19)$ & $12(48.0)$ & $11.98(0.007)^{*}$ \\
\hline 40 - 49 years & $23(27.38)$ & $7(28.0)$ & \\
\hline$>50$ years & $14(16.67)$ & $0(0)$ & \\
\hline Gender & & & $8.96(0.003)^{*}$ \\
\hline Male & $11(13.1)$ & $10(40.0)$ & \\
\hline Female & $73(86.9)$ & $15(60.0)$ & \\
\hline Marital status & & & $4.01(0.260)$ \\
\hline Single & $4(4.76)$ & $0(0)$ & \\
\hline Married & $72(85.71)$ & $25(100)$ & \\
\hline Separated & $4(4.76)$ & $0(0)$ & \\
\hline Widowed & $4(4.76)$ & $0(0)$ & \\
\hline Income (Naira**) & & & \\
\hline$<30000$ & $21(25)$ & $13(52.0)$ & \\
\hline 31000 - 150000 & $44(52.38)$ & $8(32.0)$ & $(0.037)^{*}$ \\
\hline 151000 - 300000 & $19(22.62)$ & $4(16.0)$ & \\
\hline Child gender & & & \\
\hline Male & $52(61.9)$ & $18(72.0)$ & \\
\hline
\end{tabular}




\begin{tabular}{|c|c|c|c|}
\hline Female & $32(38.1)$ & $7(28.0)$ & \\
\hline \multicolumn{4}{|c|}{ Child diagnosis } \\
\hline Cancer & $8(9.52)$ & $0(0)$ & \\
\hline HIV disease & $29(34.52)$ & $6(24.0)$ & $6.32(0.097)$ \\
\hline SCA & $43(51.19)$ & $19(76.0)$ & \\
\hline Seizures & $4(4.76)$ & $0(0)$ & \\
\hline \multicolumn{4}{|c|}{ Age at diagnosis } \\
\hline 1 - 5 years & $53(63.1)$ & $25(100)$ & \\
\hline $6-10$ years & $19(22.62)$ & $0(0)$ & $12.89(0.002)^{*}$ \\
\hline$>10$ years & $12(14.29)$ & $0(0)$ & \\
\hline \multicolumn{4}{|c|}{ Years of Care } \\
\hline 1 - 5 years & $57(67.86)$ & $19(76.0)$ & \\
\hline $6-10$ years & $23(27.38)$ & $0(0)$ & $14.80(0.0001)^{*}$ \\
\hline > 10 years & $4(4.76)$ & $6(24.0)$ & \\
\hline
\end{tabular}

\subsection{Distribution of General strain by demographic characteristics}

Table 6 shows the relationship between the caregiver's burden of general strain and the socio demographic variables of the caregivers and the children. Twenty-one (19.27\%) of the caregivers had a high score (severe burden) in general strain, among which $14(66.67 \%)$ were aged 30-39years; 18 (85.71\%) were females, 21 (100\%) were married, 11 (52.38\%) had a monthly average income of 31,000-150,000 naira. Also, among the children whose caregivers experienced the general strain burden, $15(71,43 \%)$ and 6 (28.57\%) had SCD and HIV disease respectively, all (100\%) of them were aged 0-5 years at diagnosis while $12(57.14 \%)$ had received care for 1-5 years. There was only a statistically significant relationship between severe burden of general strains and the age at diagnosis $(p=0.006)$.

Table 6 Distribution of General strain by Demographic information.

\begin{tabular}{|l|l|l|l|}
\hline & \multicolumn{1}{|c|}{$\begin{array}{c}\text { Low } \\
\mathbf{n = 8 8} \mathbf{( 8 0 . 7 3 \% )}\end{array}$} & $\begin{array}{c}\text { High } \\
\mathbf{n = 2 1}(\mathbf{1 9 . 2 7 \% )})\end{array}$ & $\begin{array}{l}\text { Chi-square } \\
\text { (p-value) }\end{array}$ \\
\hline Age Group & & & \\
\hline 20 - 29 years & $10(11.36)$ & $0(0)$ & \\
\hline 30 - 39 years & $41(46.59)$ & $14(66.67)$ & $7.40(0.06)$ \\
\hline 40 - 49 years & $23(26.14)$ & $7(33.33)$ & \\
\hline$>50$ years & $14(15.91)$ & $0(0)$ & \\
\hline Gender & & & $0.41(0.756)$ \\
\hline Male & $18(20.45)$ & $3(14.29)$ & \\
\hline Female & $70(79.55)$ & $18(85.71)$ & \\
\hline Marital status & & & $3.21(0.359)$ \\
\hline Single & $4(4.55)$ & $0(0)$ & \\
\hline Married & $76(86.36)$ & $21(100)$ & \\
\hline Separated & $4(4.55)$ & $0(0)$ & \\
\hline Widowed & $4(4.55)$ & $0(0)$ & \\
\hline
\end{tabular}




\begin{tabular}{|l|l|l|l|}
\hline \multicolumn{2}{|l|}{ Income (Naira**) } & & \\
\hline$<30000$ & $28(31.82)$ & $6(28.57)$ & \\
\hline $31000-150000$ & $41(46.59)$ & $11(52.38)$ & $0.23(0.892)$ \\
\hline $151000-300000$ & $19(21.59)$ & $4(19.05)$ & \\
\hline Child gender & & & \\
\hline Male & $56(63.64)$ & $14(66.67)$ & $0.068(1.000)$ \\
\hline Female & $32(36.36)$ & $7(33.33)$ & \\
\hline Child diagnosis & & & \\
\hline Cancer & $8(9.09)$ & $0(0)$ & \\
\hline HIV disease & $29(32.95)$ & $6(28.57)$ & $3.93(0.269)$ \\
\hline SCA & $47(53.41)$ & $15(71.43)$ & \\
\hline Seizures & $4(4.55)$ & $0(0)$ & \\
\hline Age at diagnosis & & & \\
\hline 1 - 5 years & $57(64.77)$ & $21(100)$ & \\
\hline 6 - 10 years & $19(21.59)$ & $0(0)$ & \\
\hline$>10$ years & $12(13.64)$ & $0(0)$ & \\
\hline Years of Care & & & \\
\hline 1 - 5 years & $64(72.73)$ & $12(57.14)$ & \\
\hline 6 - 10 years & $17(19.32)$ & $6(28.57)$ & \\
\hline$>10$ years & $7(7.95)$ & $3(14.29)$ & \\
\hline$*$ statistically significant $(p<0.05) ; *$ one dollar $=450$ naira RVD - Retroviral Disease; SCA- Sickle cell Anaemia \\
\hline
\end{tabular}

\section{Discussion}

In this study, more caregivers experienced severe burden in disappointment domain, followed by the general strain domain while isolation domain had the least level. The overall mean burden score experienced by caregivers in this study, which was 1.7, is low but comparable to findings from other studies where the obtained means of caregiving burden using this scale, varied between 1.98 and $2.1[9,17,18]$. The fact that majority $(>90 \%)$ of the children in this study were stable outpatients on follow up may explain the low level of burden among caregivers in this study as many related studies were among hospitalized patients. Caregivers spend a large amount of time during inpatient care, and this may influence the level of burnout and burden experienced by caregivers.

More caregivers in this study felt disappointed and the reason for this may range from lack or failure of family members to meet expected needs, to failure of social and Government support. In this part of the world, families still enjoy a high degree of communal living which provides a good family and social support system. However, with chronic diseases requiring prolonged care, this support may wane gradually leaving the entire caregiving to mothers and/or very close relatives, which is usually a source of disappointment as was found in this study. Except for children with HIV disease who receive free anti-retroviral drugs, caregivers in this study did not benefit from government support of any kind and out of pocket expenditures on chronic diseases will significantly affect the burden of these caregivers since most had low earning capacity.

There was a statistically significant relationship between the gender of the caregivers, their age, income and the burden of disappointment. Majority of these caregivers who felt disappointed were younger (<40years), females (mostly mothers), and had low monthly earning ability ( $<30,000$ naira). Low earning capacity of the caregivers as observed in this study was shown by Camargos et al [19] in a study among caregivers of children with cerebral palsy in Northeast Brazil, to have a negative and significant effect on the burden experienced by caregivers. In his study among children with cerebral palsy, Ortiz [20] found that mothers of children with chronic diseases accept higher responsibilities than other members of the family and usually play the caregiver role, and experience higher caregiving burden than males 
as was found in this study. However, other studies found no difference in the burden of care based on gender [21,22]. One possible interpretation of this fact is that although it is more common for women to look after a sick child, by assuming this role, both parents are presented with similar experiences and challenges, and the different adaptive results are related to psychosocial aspects more than to demographic features per se [21].

In this study, there was a positive correlation between the caregivers' burden of disappointment and diagnosis in the first 5 years and the duration of care. Caregivers of children whose diagnosis was made early and who have been catered for more than 10 years felt more disappointed and this has been found in other studies [17,18,19]. This finding is expected, as logically the knowledge of a child's diagnosis at an early age and providing prolonged care for that child will adversely impact on the caregiver especially where the family and social support system has dwindled and/or is weak.

General strain was the next domain of burden experienced by caregivers in this study. General strain covers physical and emotional disturbances induced by caregiving activities, caregiving problems and required time for providing caregiving services. Though second to top in our study, Pegah et al. [9] and Kobos et al. [17] reported the highest caregiving burden in general strain and disappointment similar to the finding in this study, which found a significant relationship between general strain and diagnosis of chronic disease in the first five years of life. This relationship is also true here as it is in many domain of burden where early diagnosis of the chronic illness in the child will adversely place a high burden on some caregivers.

Surprisingly, this study found that in the domains of emotional involvement, environment and isolation, few caregivers experienced severe burden of care. This finding contrasts the observation of Rubira et al. [18], who identified isolation as the area with greatest burden. The fact that over $90 \%$ of caregivers in this study have secondary and post-secondary education may explain this low level of severe burden experienced in these domains. While being educated is not a proof to the burden of caregiving, some studies have shown that better educated people are more self-confident in dealing with various life situations, have better ability to cope with problems and have access to social support which can consequently alleviate their perceived burden [23-28].

Burden of caregiving was generally low or non-existent with the very young $(<30$ years) and the older ( $>50 y e a r s)$ caregivers. It is possible that the younger caregivers received better support from their families as is the practice in this area where grandmothers and other family members show support to young mothers in the care of their children while the older mothers/caregivers have grown to adjust to the disease condition and so are less burdened by it. Ge et al. [27], however found that younger caregivers were significantly associated with high caregiver burden. More married people experienced higher burden in this study and this may probably be due to the additional need to also provide care for other members of the family as many caregivers were female (Mothers). The fact that majority of these caregivers had low monthly income will heighten their burden knowing that these chronic illnesses place a huge demand on the meagre family income.

\section{Conclusion}

In conclusion, this study found a low level of burden among caregivers of children with chronic diseases. High levels of burden were more experienced by caregivers in the domains of disappointment and general strain while the isolation domain experienced the least level. Also, these areas of burden suffered by caregivers had a positive significant correlation with the gender, age, sex and family income of the caregivers and the age at diagnosis, and duration of care.

The authors recommend a patient-centered care with the focus on improving social support. Also, the Paediatric Association of Nigeria should advocate that Government should take over the financing of medical expenses of children with chronic diseases especially those older than five years as this will ameliorate the burden of care experienced by their caregivers.

\section{Compliance with ethical standards}

\section{Acknowledgments}

We are grateful to Senior residents in the Paediatrics Department of UPTH who assisted in data collection. 


\section{Disclosure of conflict of interest}

The authors declare no conflict of interests.

\section{Statement of informed consent}

Informed consent was obtained from all caregivers/parents who participated in the study.

\section{References}

[1] Stanton AL, Revenson, TA, Tennen H. Health psychology: Psychological adjustment to chronic disease. Annual Review of Psychology. 2007; 58: 565-92.

[2] Perrin JM, Bloom SR, Gortmaker SL. The increase of childhood chronic conditions in the United States. JAMA. 2007; 297(24): 2755-9.

[3] Lantto M, Renko M, Uhari M. Changes in infectious disease mortality in children during the past three decades. The Pediatric Infectious Disease Journal. 2013; 32(9): e355-9.

[4] Salvador MS, Gomes GC, Oliveira PK, Gomes VLO, Busanello J, Xavier DM. Strategies of families in the care of children with chronic diseases. Text Context Nursing. 2015; 24(3): 662-9.

[5] Olatunya OS, Ogundare EO, Fadare JO, Oluwayemi IO, Agaja OT, Adeyefa BS, et al. The financial burden of sickle cell disease on households in Ekiti, Southwest Nigeria. ClinicoEconomics and Outcomes Research. 2015; 7: 54553.

[6] Macedo EC, da Silva LR, Paiva MS, Ramos MNP. Burden and quality of life of mothers of children and adolescents with chronic illnesses: an integrative review. Rev. Latino-Am. Enfermagem. 2015; 23(4): 769-77.

[7] Ogunlana M, Oyewole O, Falola J, Davis A, Lateef A, Adepoju M. Psychosocial problems among mothers of children with cerebral palsy attending physiotherapy outpatient department of two selected tertiary health centres in Ogun state: A pilot study. AIMS Medical Science 2019; 6(2): 158-69.

[8] Brown BJ, Okereke JO, Lagunju IA, et al. Burden of health-care of carers of children with sickle cell disease in Nigeria. Health \& Social Care in the Community. 2010;18: 289-95.

[9] Pegah P, Zahra K, Narges T, Nafise M. Caregiving burden of children with chronic diseases. Electronic Physician (ISSN: 2008-5842). 2017; 9(9): 5380-7.

[10] Valizadeh L, Joonbakhsh F, Pashaee S. Determinants of care giving burden in parents of child with cancer at Tabriz children medical and training center. J Clin Nurs Midwifery. 2014; 4(3): 13-20

[11] Northouse L, Williams A, Given B, McCorkle R. Psychosocial care for family caregivers of patients with cancer. J Clin Oncol. 2012; 30(11): 1227-34.

[12] Toledano-Toledano F, Moral de la Rubia J. Factors associated with anxiety in family caregivers of children with chronic diseases. BioPsychoSocial Medicine. 2018; 12: 20.

[13] Eke GK. Psychosocial issues experienced by parents of children with cancer in southern Nigeria. International Research Journal of Oncology. 2019; 2(2): 1-8.

[14] Onubogu UC, Owate E. Pattern of acute asthma seen in Children Emergency Department of the River State University Teaching Hospital, Port Harcourt, Nigeria. Open Journal of Respiratory Diseases. 2019; 9: $101-11$.

[15] Elmståhl S. Instructions for the Caregiver Burden Scale. 2019.

[16] Elmståhl S, Dahlrup B, Ekström H, Nordell E. The association between medical diagnosis and caregiver burden: a cross-sectional study of recipients of informal support and caregivers from the general population study 'Good Aging in Skåne', Sweden. Aging Clinical Exp Research 2017 Dec 13.

[17] Kobos E, Imiela J. Factors affecting the level of burden of caregivers of children with type 1 diabetes. Appl Nurs Res. 2015; 28(2): 142-9.

[18] Rubira EA, Marcon SR, Belasco AGS, Gaíva MAM, Espinosa MM. Burden and quality of life of caregivers of children and adolescents with chemotherapy treatment for cancer. Acta Paul Enferm. 2012; 25(4): 567-73.

[19] Camargos AC, de Lacerda TT, Viana SO, Pinto LR, Fonseca ML. [Assessment of the caregiver burden of children with cerebral palsy using the Burden Interview Scale]. Rev Bras Saúde Matern Infantil. 2009; 9(1): 31-7. 
[20] Ortiz MC, de Lima RA. Experiences of families with children and adolescents after completing a cancer treatment: support for the nursing care. Rev Latinoam Enferm. 2007; 15(3): 411-7.

[21] Toledano-Toledano F, Domínguez-Guedea MT. Psychosocial factors related with caregiver burden among families of children with chronic conditions. BioPsychoSocial Medicine. 2019: 13: 6.

[22] Deater-Deckard K, Panneton R. Parental stress and early child development: adaptive and maladaptive outcomes. Cham: Springer International Publishing. 2017.

[23] Adib-Hajbaghery M, Ahmadi B. Caregiver Burden and Its Associated Factors in Caregivers of Children and Adolescents with Chronic Conditions. IJCBNM. 2019; 7(4): 258-69.

[24] Piran P, Khademi Z, Tayari N, Mansouri N. Caregiving burden of children with chronic diseases. Electron Physician. 2017; 9: 5380-7.

[25] Dada MU, Okewole NO, Ogun OC, Bello Mojeed MA. Factors associated with caregiver burden in a child and adolescent psychiatric facility in Lagos, Nigeria: a descriptive cross sectional study. BMC Pediatrics. 2011; 11: 110.

[26] Hu X, Dolansky MA, Hu X, et al. Factors associated with the caregiver burden among family caregivers of patients with heart failure in southwest China. Nursing \& Health Sciences. 2016; 18: 105-12.

[27] Ge L, Mordiffi S. Factors Associated With Higher Caregiver Burden Among Family Caregivers of Elderly Cancer Patients. Cancer Nursing. 2017; 40: 471-8.

[28] Adelman RD, Tmanora L, Delgado D, et al. Caregiver Burden: A Clinical Review. Journal of the American Medical Association. 2014; 311: 1052-60.

[29] Paul NI, Duru CO. Childhood Non Communicable Diseases (NCDs) in Two Tertiary Hospitals in South-South Nigeria. Archives of Current Research International. 2020; 20(1): 13-23.

[30] Emodi IJ, Ikefuna AN, Ujunwa FA, Chinawa JM. Synopsis of noncommunicable diseases in children admitted to the paediatric ward of the university of Nigeria teaching hospital (UNTH) Enugu, Nigeria: A ten year review. Niger Med J. 2014; 55(6): 499-503.

[31] Yawson AE, Abuosi AA, Badasu DM, Atobrah DA, Adzei FA, Anarfi JK. Noncommunicable diseases among children in Ghana: Health and social concerns of parent/caregivers. African Health Sciences. 2016; 16(2): 378-388. 